\title{
FUZZY ENERGY AWARE GRAPH BASED ROUTING (FEAGR) IN WIRELESS SENSOR NETWORKS
}

\author{
Amarappa Pagi ${ }^{1}$, Abdul Lateef Haroon P S ${ }^{2}$, Manjunath $\mathrm{K} \mathrm{M}^{\mathbf{3}}$, Ulaganathan $\mathrm{J}^{\mathbf{4}}$ \\ ${ }^{1}$ Assistant Professor, Dept of ECE, BITM Bellary - 583104, Karnataka, India \\ ${ }^{2}$ Assistant Professor, Dept of ECE, BITM Bellary - 583104, Karnataka, India \\ ${ }^{3}$ Assistant Professor, Dept of ECE, BITM Bellary - 583104, Karnataka, India \\ ${ }^{4}$ Assistant Professor, Dept of ECE, BITM Bellary - 583104, Karnataka, India
}

\begin{abstract}
A WSN system provides wireless connectivity back to the wired world and distributed nodes. Routing is the main operation in wireless sensor (WSN). In this work, the energy of a node, distance of a node from the current node and the angle made by a node with the sink node. The fuzzy system estimates the chance of a node capable of handing over a packet to the surrounding nodes. The chance is estimated based on the distance, angle made by a node with the sink and energy of the node. Dijkstra's algorithm is used to find an efficient route from a source to Base station. The path from the source node to the sink node is recorded and the packet is routed on the identified path. The proposed approach increases the speed and accuracy. since it considers all the three relevant parameters.
\end{abstract}

Keywords: Fuzzy inference, flat routing, shortest path routing.

\section{INTRODUCTION}

A wireless sensor network (WSN) in its simplest form can be defined as a network of (possibly low size and lowcomplex) devices denoted as nodes that can sense the environment and communicate the information gathered from the monitored field through wireless links; the data is forwarded, possibly via multiple hops relaying, to a sink that can use it locally, or is connected to other networks (e.g., the Internet) through a gateway[1].Wireless sensor networks are composed of hundreds of tiny low-cost sensor nodes, capable of measuring various physical events, performing computations and most importantly communicating with each other. Each node in this network includes components such as communication device (antenna), low memory, sensor circuit, weak processor, limited energy supply, etc. sensor networks (WSNs) have been used in various applications like military, Health monitoring, nature for flood detection, environment etc. These networks are also used in environments that are difficult to access by humans, such as volcanoes or military areas.

There are various challenges in WSN because of its special properties. One of these challenges is nodes' limited power supply. Power supply in most cases is irreplaceable and impossible to recharge. So in these networks we should use methods that take the lowest level of energy from nodes. Sensed data by the nodes should be transferred to base station for processing and decision making. This station is called sink. A packet to reach the sink from source node must pass through several nodes. Routing is an issue in WSN which solves the problems of energy up to some events.
These Routing algorithms are divided into three categories based on network structure: flat, hierarchical, and location of routing. In flat routing, all sensor nodes are treated uniformly. When a node needs to send the data it calculates the shortest path from source to the base station then it sends the sensed data to the base station through intermediate nodes. Flat routing algorithms like Direct Diffusion (DD), Sensor Protocols for Information via Negotiation (SPIN), Minimum Cost Forwarding Algorithm are given in $[2,3]$.

In hierarchical routing, some nodes act as a local station and may have more energy than other nodes. This structure is also called clustering. Some of hierarchical routing algorithms are: Low Energy Adaptive Clustering Hierarchy (LEACH), Power-Efficient Gathering in Sensor Information Systems (PEGASIS) [4, 5]. In the location-based routing, each node is aware of location of other nodes. Algorithms such as Geographic Adaptive Fidelity (GAF) and Geographic and Energy Aware Routing (GEAR) are in this category $[6,7]$. Our paper proposes fuzzy based method for flat routing. Unlike the normal methods a fuzzy system is able to work well with disparate and inaccurate data.

Many approaches and techniques for routing are explored for the optimization of energy usage in wireless sensor networks. Fuzzy logic is one of the techniques which attempts for efficient utilization of energy have been made. To know the state-of-the-art in routing techniques in wireless sensor networks, we studied the existing literature and the following works are found more relevant and similar to our approach. 
The work in [8] presents a generalized fuzzy logic based approach for energy-aware routing in wireless sensor networks. This approach is soft and tunable and hence it can accommodate sensor networks comprising of different types of sensor nodes having different energy metrics. It can be tuned for different network and node conditions. Fuzzy logic controller is used to reduce the communication overheads during flooding are given in [9]. Different algorithms are proposed with respect to a number of factors such as application areas, usage condition, power, aggregation parameters [10]. One of the most important features of routing algorithms is their flexibility and ability to selforganize themselves according to such parameters. Two algorithms, i. e., Earliest-First Tree (EF-Tree) and SourceInitiated Dissemination (SID) are used to disseminate data, and employ a fuzzy method to choose cluster head, and to switch between two methods. It increases the energy efficiency.

Fuzzy logic is used to perform role assignment during route establishment and maintenance [11]. Three-Dimensional Fuzzy Routing based on the Receiving Probability (SFRRP) is proposed in [12]. In this method data packets are transmitted by hop-to-hop delivery to the base station. Work in [13] presents two online routing algorithms based on fuzzy logic, namely fuzzy maximum lifetime algorithm and fuzzy multi-objective algorithm.

A Fuzzy Energy Aware tree-based Routing (FEAR) protocol is discussed in [14] that aim to enhance existing tree-based routing protocols and prolong the network's life time by considering sensors' limited energy. Each node maintains a list of its neighbors in order to use neighbors' links in addition to the parent-child links. A multi-hop clustering algorithm is proposed in [15] using the fuzzy logic improvement methods. The selection of cluster heads is based on four descriptors; residual energy as primary parameter, node proximity to its neighbors (centrality), distance to base station and node concentration.

The problem of fault tolerant routing is approached in wireless sensor networks using fuzzy logic is approached in [16]. The problem is broken into two sub problems. The first sub problem is designing a routing module and the second one retrofitting the designed module in a way that answering to these two sub problems leads to the final solution of the main problem. The method utilizes multi-path redundancy and routing techniques in order to increase the suggested fault tolerant routing. $\mathrm{LEACH}$, one of the most famous clustering mechanisms is explained in [17]; it elects a cluster head $(\mathrm{CH})$ based on a probability model. This paper improves LEACH protocol using Fuzzy Logic (LEACHFL).

Table 1: A comparative study of reported works

\begin{tabular}{|l|l|l|l|}
\hline $\begin{array}{l}\text { Refere } \\
\text { nce }\end{array}$ & $\begin{array}{l}\text { Type of } \\
\text { routing }\end{array}$ & Technique & Parameters \\
\hline$[8]$ & $\begin{array}{l}\text { Energy } \\
\text { aware }\end{array}$ & Fuzzy logic & Energy, Distance \\
\hline
\end{tabular}

\begin{tabular}{|c|c|c|c|}
\hline [9] & $\begin{array}{l}\text { Direct } \\
\text { diffusio } \\
\mathrm{n}\end{array}$ & Fuzzy & $\begin{array}{l}\text { Traffic load, Energy, } \\
\text { Weight. }\end{array}$ \\
\hline$[10]$ & $\begin{array}{l}\text { Data } \\
\text { Dissemi } \\
\text { nation }\end{array}$ & $\begin{array}{l}\text { Earliest first } \\
\text { tree, source } \\
\text { initiated } \\
\text { disseminati } \\
\text { on. }\end{array}$ & $\begin{array}{l}\text { Energy, } \\
\text { Concentration, } \\
\text { Centrality. }\end{array}$ \\
\hline [11] & $\begin{array}{l}\text { Networ } \\
\mathrm{k} \text { Role } \\
\text { based }\end{array}$ & Fuzzy & $\begin{array}{l}\text { No of hops, Node } \\
\text { suitability, Battery } \\
\text { level. }\end{array}$ \\
\hline [12] & $\begin{array}{l}\text { Static } \\
\text { Three } \\
\text { dimensi } \\
\text { onal }\end{array}$ & Fuzzy & $\begin{array}{l}\text { Distance, No of } \\
\text { neighbors, Receiving } \\
\text { probability }\end{array}$ \\
\hline$[13]$ & Online & Fuzzy & Battery Level \\
\hline [14] & $\begin{array}{l}\text { Energy } \\
\text { Aware }\end{array}$ & Fuzzy & $\begin{array}{l}\text { Residual energy, } \\
\text { Distance, Depth }\end{array}$ \\
\hline [15] & $\begin{array}{l}\text { Energy } \\
\text { Based } \\
\text { Clusteri } \\
\text { ng }\end{array}$ & Fuzzy logic & $\begin{array}{l}\text { Energy, } \\
\text { Concentration }\end{array}$ \\
\hline [16] & $\begin{array}{l}\text { Novel } \\
\text { Fault } \\
\text { Toleran } \\
\mathrm{t}\end{array}$ & Fuzzy logic & Residual Energy \\
\hline [17] & $\begin{array}{l}\text { Cluster } \\
\text { Based }\end{array}$ & Fuzzy logic & $\begin{array}{ll}\text { Distance, } & \text { Node } \\
\text { density, Battery level }\end{array}$ \\
\hline
\end{tabular}

The remainder of this paper is organized as follows: In Section 2 preliminary comments on the proposed method are discussed. The proposed methodology is presented in Section 3. Simulation results and performance parameters of the proposed method is evaluated in Section 4. Finally Section 5 concludes the work.

\section{PRIMARY DESCRIPTION}

In centralized method the base stations involve for decision making. In our proposed method, the source node decides the path for routing, based on the threshold value. The nodes with chance value below the threshold are marked as non reachable nodes. Because of this characteristic, the algorithm will be quicker. The source node uses the fuzzy parameters to select the next node. In this method, the angle, distance and energy node relative to the sink node fuzzy parameters are used in decision making. A node that has an angle of approximately 45 degree with the sink node provides minimum distance to the sink. If the angle between the next node and the sink node deviates much from 45 degree, its chance of selection for routing will be lesser.

It is wise to involve parameter of remaining energy of neighbor nodes in the decision making. Since the current node does not have access to the energy remaining neighbors, it should ask them to notify it for their remaining energy. It is followed by a lot of sending and receiving energy. Since we know that sending and receiving takes a lot of nodes energy, it is better to choose another way. In our proposed method, instead of the residual energy of nodes, 
we will involve the input parameters such as nodes angle, distance and energy of neighboring nodes and output is chance in decision making. The proposed algorithm is detailed in the next section.

\section{PROPOSED ALGORITHM}

The proposed work and algorithm are given in this section. A node assigns a value to each of its neighbors. This value is the chance of the node to be selected as next node. In our proposed model we have used three input variables which are Angle, Distance and Energy and output variable is chance of the node to be selected as neighbor. Stages of the fuzzy inference are shown in Figure 1.

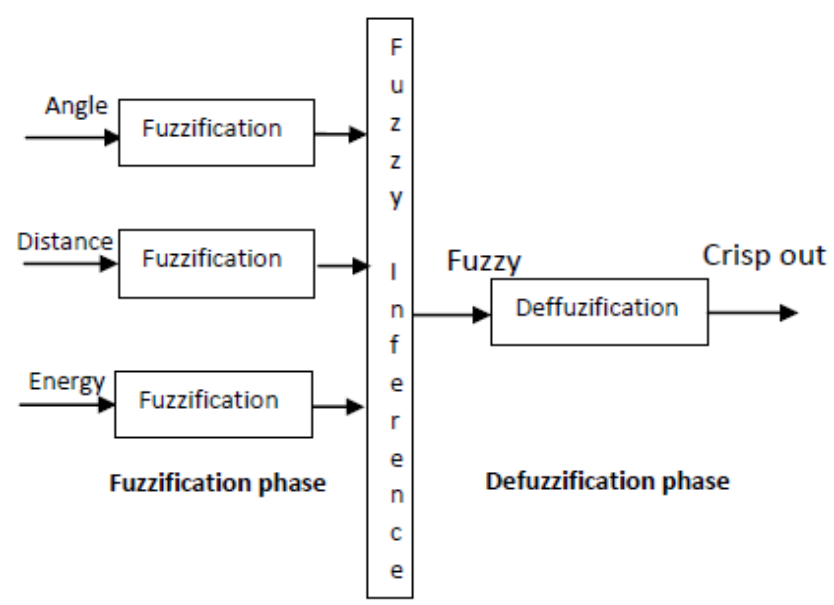

Inference phase

Figurel. Fuzzy system components

Fuzzy system has some advantages such as being able to work well with heterogeneous and inaccurate inputs and it does not require heavy processing. The first step in this fuzzy system is the fuzzification. It is done by membership functions. We need three membership functions to fuzzify, one for Angle of a node, one for Distance and another for Energy of a node. Three membership functions are presented below. Figure 2 shows the Triangular membership function for distance. These functions are used due to their suitability for real-time operation. Similarly triangular membership functions for angle and energy defined.

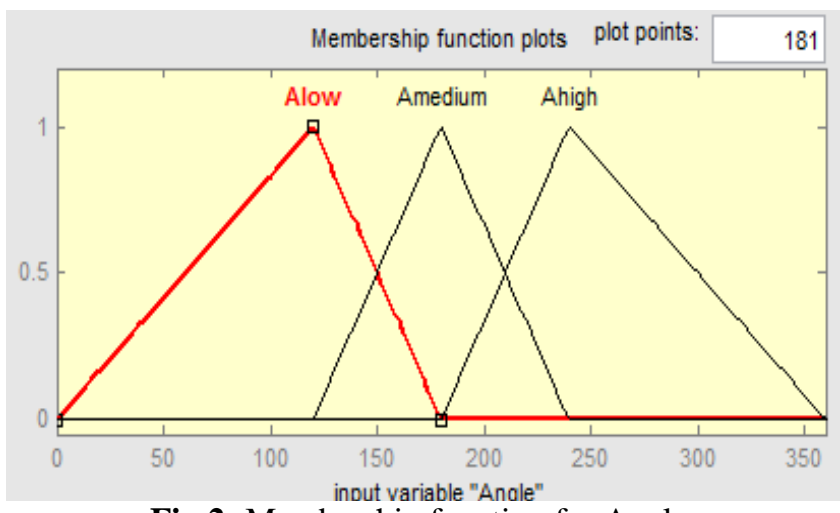

Fig 2: Membership function for Angle

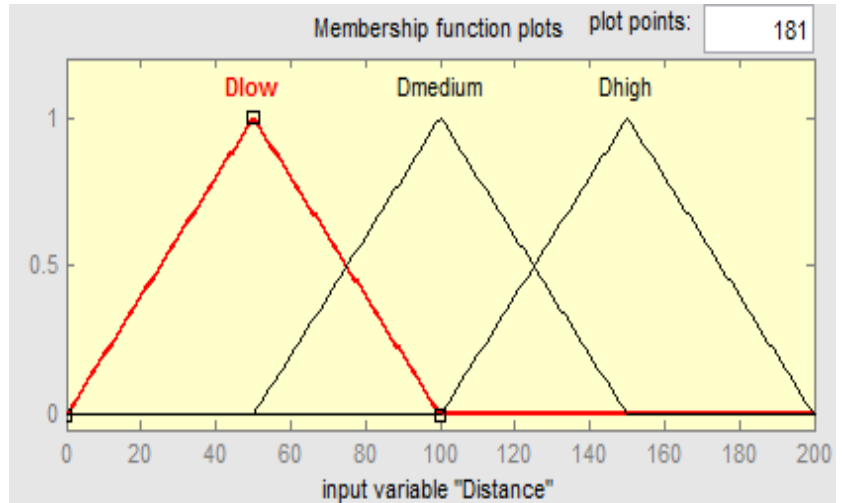

Fig.3: Membership function for Distance

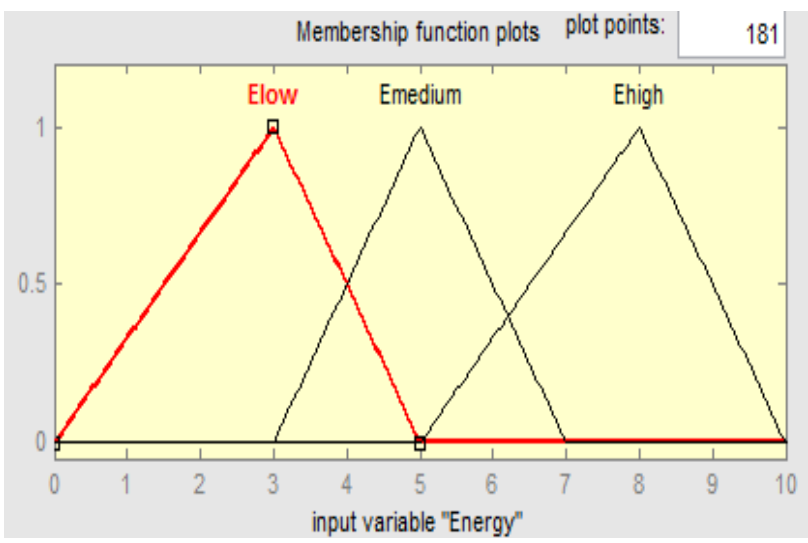

Fig 4: Membership function for Energy

Figure 5 shows the angle between a node and sink node. The angles nearer to 45 degree are treated as high. The angles between 90 to 180 and 270 to 360 are treated as medium, whereas the angles between 180 degree to 270 degree are not preferred. This is mainly because, the nodes are assumed to be present at the center of the origin. The sink node lies in the imaginary region of $2 \mathrm{D}$ plane, which extends from 0 degree to 90 degree, i.e., in the first quadrant. The second and fourth quadrants are considered as medium vicinity because they have a possibility of convergence with the first quadrant. But the third quadrant is in opposite direction of the first quadrant, which is treated as low angle region.



Fig 5: The preferred orientation of the path between a node and the sink 
After fuzzification, the next step is fuzzy inference. In the inference phase, the fuzzy output value is obtained from the fuzzy inputs. Fuzzy inference system used in this expert system is Mamadani's fuzzy system. Mamdani fuzzy system is a simple rule-based method that does not require complex computations and control system using if-then rules. In the next step, the fuzzy values are converted to crisp. It is the inverse of fuzzification and is known as defuzzification. The defuzzification step requires a membership function. Twenty seven levels are considered for the output values so that the input differences are clearly defined in the output and accuracy is increased. The employed membership function shown in Figure 6.

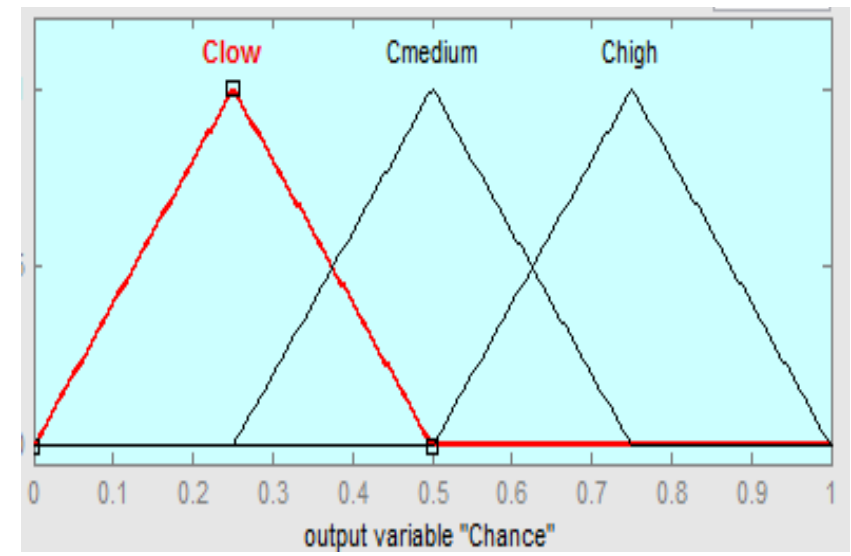

Fig 6: Membership function in order to estimate the chance of selecting the node

The node performs decision making by using Mamdani rulebased technique and existing rules for the chance of selecting the neighboring node. Some of the rules employed in this work are given in Table 2.

Table 2 Rule-base used with fuzzy inference system

\begin{tabular}{|c|c|c|c|c|}
\hline \multirow{2}{*}{$\begin{array}{l}\text { Rule } \\
\text { No. }\end{array}$} & \multicolumn{3}{|c|}{ Input parameters } & \multirow{2}{*}{$\begin{array}{l}\text { Output } \\
\text { Chance }\end{array}$} \\
\hline & Angle & $\begin{array}{l}\text { Distanc } \\
\mathrm{e}\end{array}$ & Energy & \\
\hline 1. & Low & Low & Low & Medium \\
\hline 2. & Low & Low & Medium & Medium \\
\hline 3. & Low & Low & High & High \\
\hline 4. & Low & $\begin{array}{l}\text { Mediu } \\
\mathrm{m}\end{array}$ & Low & Low \\
\hline 5. & Low & $\begin{array}{l}\text { Mediu } \\
\mathrm{m}\end{array}$ & Medium & Medium \\
\hline 6. & Low & $\begin{array}{l}\text { Mediu } \\
\mathrm{m}\end{array}$ & High & Medium \\
\hline 7. & Low & High & Low & Low \\
\hline 8. & Low & High & Medium & Low \\
\hline 9. & Low & High & High & Medium \\
\hline 10. & Medium & Low & Low & Low \\
\hline 11. & Medium & Low & Medium & Medium \\
\hline 12. & Medium & Low & High & Medium \\
\hline 13. & Medium & $\begin{array}{l}\text { Mediu } \\
\mathrm{m}\end{array}$ & Low & Low \\
\hline
\end{tabular}

\begin{tabular}{|l|l|l|l|l|}
\hline 14. & Medium & $\begin{array}{l}\text { Mediu } \\
\mathrm{m}\end{array}$ & Medium & Medium \\
\hline 15. & Medium & $\begin{array}{l}\text { Mediu } \\
\mathrm{m}\end{array}$ & High & Low \\
\hline 16. & Medium & High & Low & Low \\
\hline 17. & Medium & High & Medium & Low \\
\hline 18. & Medium & High & High & Medium \\
\hline 19. & High & Low & Low & Low \\
\hline 20. & High & Low & Medium & Low \\
\hline 21. & High & Low & High & Low \\
\hline 22. & High & $\begin{array}{l}\text { Mediu } \\
\mathrm{m}\end{array}$ & Low & Low \\
\hline 23. & High & $\begin{array}{l}\text { Mediu } \\
\mathrm{m}\end{array}$ & Medium & Medium \\
\hline 24. & High & $\begin{array}{l}\text { Mediu } \\
\mathrm{m}\end{array}$ & High & Low \\
\hline 25. & High & High & Low & Low \\
\hline 26. & High & High & Medium & Low \\
\hline 27. & High & High & High & Medium \\
\hline
\end{tabular}

Several methods are used to perform defuzzification. Some of these methods are: Center of Area (COA), Center of Gravity (COG), Mean of Maxima (MeOM) etc. We use COA method for defuzzification. Equation (1) is used to obtain the crisp value from the fuzzy value.

$$
\alpha=\frac{\int_{z} \mu_{A}(X) z d z}{\int_{z} \mu_{A}(z) d z}
$$

where $\alpha$ is the non-fuzzy output for the fuzzy system (z) and $\mu_{A}(X)$ is membership function of $\mathrm{X}$ in $\mathrm{A}$.

\section{SIMULATION AND RESULTS}

MATLAB ver 7.14.0.739 (R2012a) is used for simulation of our work. The simulation model and procedure is as below. The simulation model consists of an Area of $100 \times 100 \mathrm{~m}^{2}$ and node parameters are Angle (0 to 360), Distance (0 to $200 \mathrm{~m}$ ) and Energy (0 to 10 Joule. The details of node parameters are summarized in Table 3.

Table 3 Membership function and parameters used

\begin{tabular}{|lc|l|l|l|}
\hline \multirow{2}{*}{ Parameter } & \multicolumn{3}{|l|}{ Membership functions } \\
\cline { 3 - 5 } & Low & Medium & High \\
\hline $\begin{array}{l}\text { Angle (in } \\
\text { degrees) }\end{array}$ & $0-90$ & $\begin{array}{l}90-180, \\
270-360\end{array}$ & $180-270$ \\
\hline $\begin{array}{l}\text { Distance (in } \\
\text { m) }\end{array}$ & $0-100$ & $100-150$ & $150-200$ \\
\hline $\begin{array}{l}\text { Energy (in } \\
\text { Joule) }\end{array}$ & $0-5$ & $5-8$ & $8-10$ \\
\hline
\end{tabular}


Simulation Procedure: Algorithm

1. Node deployment: Initializing the network with an area of $100 * 100$ and deploying the nodes randomly in the network.

2. Fuzzify the input parameters, the angle, distance and energy. i.e., convert the crisp values into fuzzy ranges. Angle is in the range of 0 to 360 degree), Distance (0 to $200 \mathrm{~m})$ and Energy (0 to 10 joule). Linguistic variables such as Low, Medium and High are used for fuzzifying the input parameters. Triangular membership functions are used to determine the degree of membership due to their smoothness for real time operation. 27 rules (IfThen) rules are generated for three inputs in order to determine the behavior of the system.

3. Decision making: Applying fuzzy inference system to the network using parameters i.e. input parameter and output is chance.

4. Selection of a neighbor node: The neighbor node is selected based on the chance. If the chance is above the threshold, the node is included in the potential graph; otherwise it is suppressed by setting larger values for the distance to that node.

5. Computing the distance matrix to find the distance value for each node the node which is having minimum distance that can be selected as neighbor node for further transmission.

6. Routing: We find a shortest path from source node to sink node using Dijkstra's algorithm.

The focus of the paper is mainly the analysis of the performance of the network with respect to Throughput, Average energy and Time, which are defined as follows.

1. Throughput: Throughput is the rate of successful message delivery over a communication channel. This data may be delivered over a physical or logical link, or pass through a certain network node. The throughput is usually measured in bits per second (bit/s or bps), and sometimes in data packets per second or data packets per time slot.

2. Average Energy: This is the average energy consumed while routing a packet from a source node to a base station in each case study of hundred experiments. An experiment involves routing a packet in a WSN comprising n number of nodes, where $\mathrm{n}$ varies $2 \leq \mathrm{n} \leq 50$.

3. Time: This is the time needed to route the packet from source node to sink.

Table 4: Sample values of performance metrics

\begin{tabular}{|l|l|l|l|}
\hline $\begin{array}{l}\text { No. of } \\
\text { Nodes }\end{array}$ & $\begin{array}{l}\text { Throughp } \\
\text { ut }\end{array}$ & $\begin{array}{l}\text { Average } \\
\text { Energy }\end{array}$ & $\begin{array}{l}\text { Average time } \\
\text { Elapsed }\end{array}$ \\
\hline 2 & 53 & 2.19 & 0.0354 \\
\hline 5 & 84 & 2.23 & 0.0440 \\
\hline 10 & 93 & 2.44 & 0.1155 \\
\hline 12 & 95 & 2.48 & 0.1603 \\
\hline 15 & 94 & 2.56 & 0.2376 \\
\hline 20 & 97 & 2.45 & 0.4307 \\
\hline 22 & 96 & 2.58 & 0.4844 \\
\hline
\end{tabular}

\begin{tabular}{|l|l|l|l|}
\hline 25 & 99 & 2.55 & 0.6336 \\
\hline 30 & 100 & 2.55 & 0.8952 \\
\hline 32 & 99 & 2.42 & 1.0149 \\
\hline 35 & 100 & 2.44 & 1.2072 \\
\hline 40 & 100 & 2.5 & 1.6558 \\
\hline 42 & 100 & 2.65 & 1.8186 \\
\hline 45 & 99 & 2.5 & 2.0242 \\
\hline 50 & 100 & 2.48 & 2.4756 \\
\hline
\end{tabular}

It can be clearly observed from the table that the evaluation parameters, throughput, average energy and time, increase with increase in size of the network. The throughput increases since the number of potential nodes in the network will be more for networks with large number of nodes. The average energy consumed increases with the increasing size of the network, since the routing happens through more nodes, consuming more energy. The time consumed depends on the number of nodes in the network. It is mainly because of the time complexity of Dijkstra's algorithm.

Throughput is the rate of successful message delivery over a communication channel. Figure 7 shows the throughput for varying number of nodes. As the number of nodes increases throughput also increases. This data may be delivered over a physical or logical link, or passed through a certain network node. It is clearly observed that the throughput of about $100 \%$ is achieved for a network with minimum of 15 nodes. This is mainly because with more nodes in the network, the number of potential nodes increases and hence the number of drops comes down.

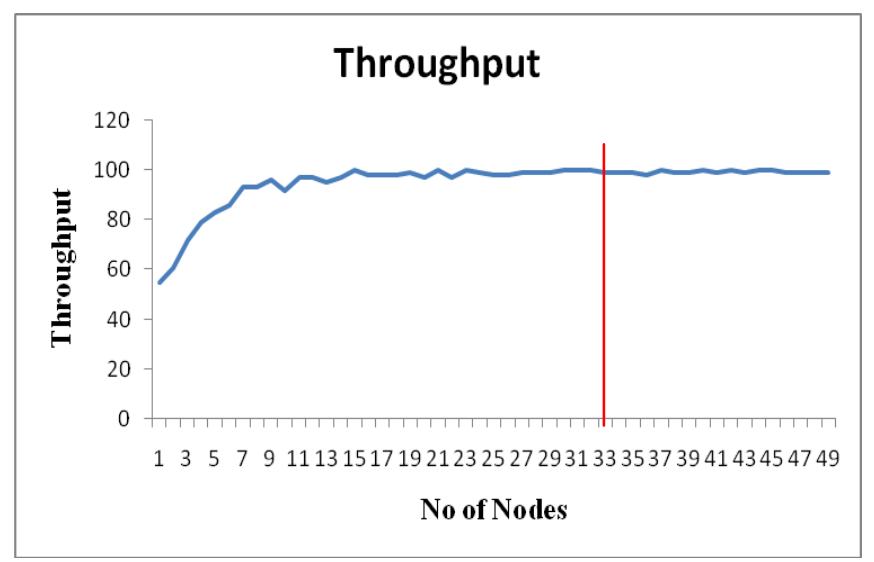

Fig 7: Throughput of the network for varying number of nodes

Figure 8 shows the average energy required to transmit packets from the source node to the sink. As the number of nodes increases the average energy required to transmit a packet is also increases. The decrease in energy causes losing of packet. But an average energy of about $2.5 \mathrm{~J}$ is sufficient to transmit. The routing happens between the source and sink node through a set of nodes. The routing is applied only through the potential nodes with chance above the threshold. Hence, the path lengths are shorter, involving 
minimum number of nodes. For every hop through a node, we assume energy of $1 \mathrm{~J}$ is consumed. Hence, the average energy consumed is estimated based on the results of 100 iterations of the algorithm.

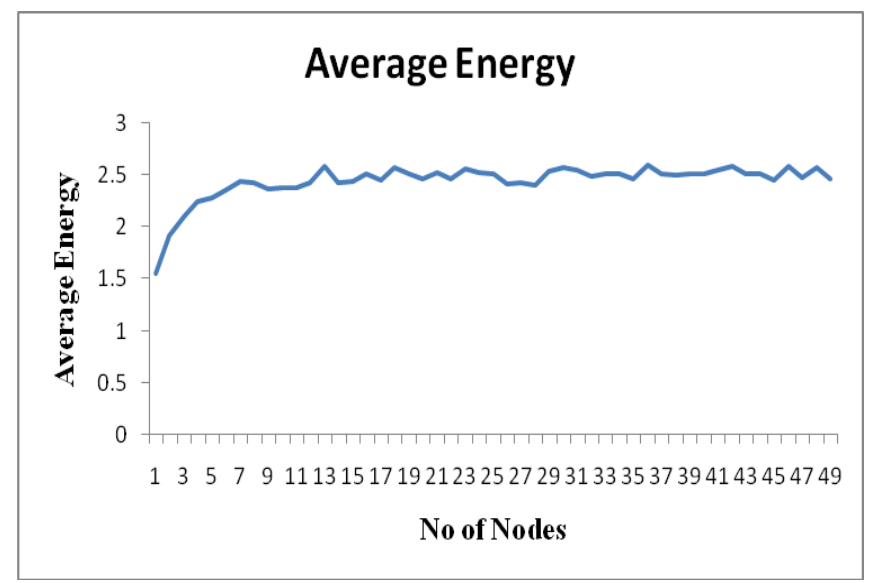

Fig 8: Average Energy consumed during routing

Figure 9 shows the average time needed to route the packets from source to sink. In networks comprising the number of nodes varying from 2 to 50.Naturally for networks with smaller number of nodes the time taken for routing is smaller. With increase in number of nodes more time is needed to route a packet through different nodes. It is mainly because the Dijkstra algorithm finds the shortest route from source node to the sink node. The algorithm treats the entire network as a graph and finds the shortest path from the source to all other nodes. In this methodology the Dijkstra algorithm is used to compute the shortest path between source node and all other nodes and finally only the path identified between the source and sink is retained and plotted. The curve is almost parabolic in nature hence as the network grows we require more time for routing.

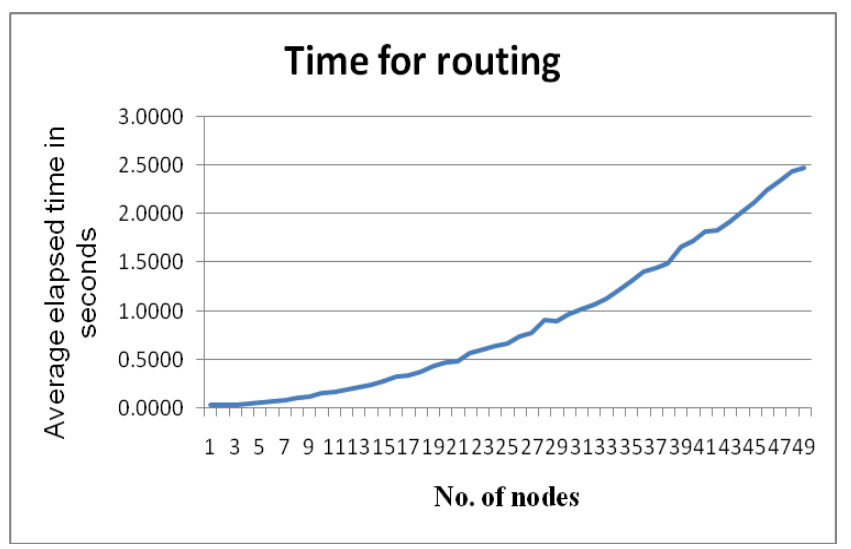

Fig 9: Time for routing

Figure 10 Shows the shortest path from source node to sink based on minimum distance, as found by Dijkstra algorithm .The nodes with chance greater than the threshold value are being selected as neighbors. In figure 10 the node 1 is source node and node 5 is a sink node. The packets from node 1 to node 5 are transmitted through the neighbor node such as node 2 .

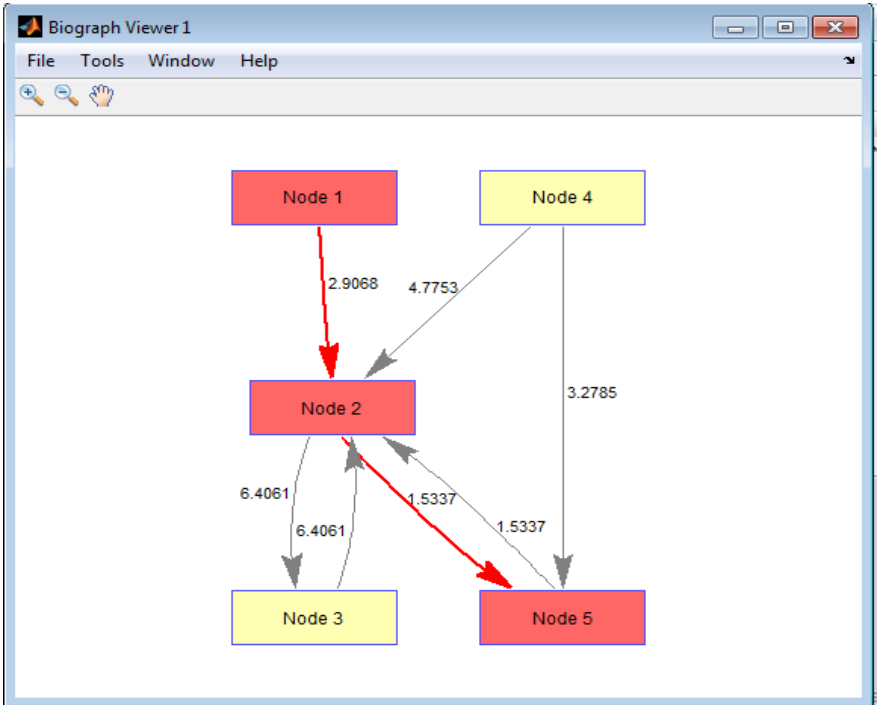

Fig 10: Shortest path from source node to sink node

The nodes 3 and 4, which are marked with yellow, are nonpotential nodes, which are not involved in routing. The packet is being routed from node 1 to node 5 through node 2 . The node 2 is considered as a potential node based on its chance value, derived from angel, distance and energy.

\section{CONCLUSION}

The proposed method is centralized and all operations are performed by the source node. Routing is carried out only via the nodes on the identified path, having energy greater than the threshold. Determining the chance of a node is performed by a fuzzy inference system. The proposed method uses angle, distance and energy of a node, to determine the chance of that node. The method is suitable for the networks with the centralized control and the source node with sufficient energy. It increases the network lifetime significantly, since it is energy-aware. However, the methodology leaves scope for improvement in terms of dynamic routing, efficient algorithms for shortest path computation, elimination of non-potential nodes from shortest path computation and the like.

\section{REFERENCES}

[1] Pon Mahizh, Muthuselvi, Dr.V.Kavitha, A Maximum Residual Energy for WSN Using a Novel A-Star Algorithm And Neuro Fuzzy Approach, International Journal on Current Issues of Computer Science, 1, 1, (2013)

[2] B. Meenakshi, P. Anandhakumar, Optimization of Energy Consumption by Fuzzy Based Routing In Wireless Sensor Network, IOSR Journal of Electronics and Communication Engineering (IOSRJECE) ISSN : 2278-2834, 2, 1, (2012), PP 3135

[3] A.Narendrakumar1 K.Thyagarajah, Enhancing Wireless Sensor Network Routing by High Quality Link Set Cooperative Routing Algorithm, International Journal of Engineering and Technology (IJET) ISSN : 0975-4024, 5,5, (2013) 
[4] Naveen Sharma and Anand Nayyar, A Comprehensive Review of Cluster Based Energy Efficient Routing Protocols for Wireless Sensor Networks, International Journal of Application or Innovation in Engineering \& Management (IJAIEM), 3, 1, (2014) ISSN $2319-4847$

[5] Poonam Shrivastava, Srija Unnikrishnan, Analysis of LEACH and Its Variants for Routing In Wireless Sensor Networks, Poonam Shrivastava et al Int. Journal of Engineering Research and Applications ISSN : 2248-9622, 3, 6, (2013), pp.386-389

[6] Deepti Gupta and Ajay K Sharma, Fuzzy Cost Metric based Adaptive (FCMA) Routing Protocols for WSNs, International Journal of Sensor and Its Applications for Control Systems, 1, 1 (2013), pp.1322

[7] S.BaraniDr.C.Gomathy, Energy Aware Routing Algorithm For Wireless Sensor Network, Indian Journal of Computer Science and Engineering (IJCSE) ISSN : 0976-5166, 2, 6, (2012),pp.850-861

[8] Tarique Haider1 and Mariam Yusuf, A Fuzzy Approach to Energy Optimized Routing for Wireless Sensor Networks, The International Arab Journal of Information Technology, 6, 2, (2009), pp.179-185

[9] Faraneh Zarafshan, Abbas Karimi, and S. A. R. AlHaddad, A Novel Fuzzy Diffusion Approach for Improving Energy Efficiency in Wireless Sensor Networks, International Journal of Machine Learning and Computing, 2, 4, (2012), pp.506-509

[10] Zohre. Arabil and Yaghoub Khodaei, HERF: A Hybrid Energy Efficient Routing using a Fuzzy Method in Wireless Sensor Networks, International Journal of Distributed and Parallel Systems (IJDPS), 1, 1, (2010), pp.01-11

[11] Antonio M. Ortiz, Fernando Royo, Teresa Olivares and Jose C. Castillo, Fuzzy-Logic Based Routing for Dense Wireless Sensor Networks, Telecommunication system DOI 10.1007/s11235011-9597-y

[12] Mohammad Samadi Gharajeh 1and Sohrab Khanmohammadi, Static Three Dimensional Fuzzy Routing Based on the Receiving Probability in Wireless Sensor Networks, 2, Computers, (2013), pp.152-175

[13] Mahmood R. Minhas, Sathish Gopalakrishnan and Victor C. M. Leung, Fuzzy Algorithms for Maximum Lifetime Routing in Wireless Sensor Networks, IEEE Wireless Communications, 11, 6, (2004), pp.6-28

[14] Iman M. ALMomani, Maha K. Saadeh, FEAR: Fuzzy-Based Energy Aware Routing Protocol for Wireless Sensor Networks, International Journal of Communications, Network and System Sciences, (2011), pp. 403-415

[15] M. Taheri Bushehr, Iran Yousef S. Kavian, Energy Efficient Clustering Algorithm for Wireless Sensor Networks using Fuzzy Logic, International Journal of Computer Applications , 89, 14, (2014), pp.01-05

[16] Mostafa Vakili Fard , Sayyed Majid Mazinani , Sayyed and Ahmad Hoseini, Introducing a Novel Fault Tolerant Routing Protocol in Wireless Sensor
Networks using Fuzzy Logic, International Journal of Computer Science and Information Technology (IJCSIT), 5, 5, (2013), pp.171-176

[17] Ge Ran, Huazhong Zhang and Shulan Gong, Improving on LEACH Protocol of Wireless Sensor Networks Using Fuzzy Logic, Journal of Information \& Computational Science, 7, 3, (2010), pp.767-775 